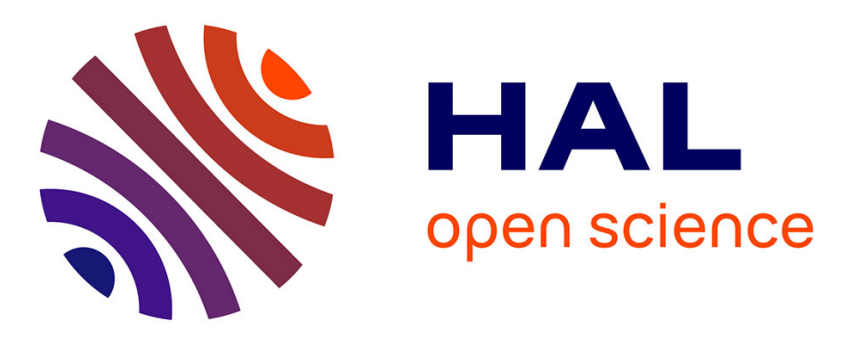

\title{
Effects of the Chemical and Structural Properties of Silane Monolayers on the Organization of Water Molecules and Ions at Interfaces, from Molecular Dynamics Simulations
}

\author{
Solène Lecot, Antonin Lavigne, Zihua Yang, Yann Chevolot, Magali
}

Phaner-Goutorbe, Christelle Yeromonahos

\section{To cite this version:}

Solène Lecot, Antonin Lavigne, Zihua Yang, Yann Chevolot, Magali Phaner-Goutorbe, et al.. Effects of the Chemical and Structural Properties of Silane Monolayers on the Organization of Water Molecules and Ions at Interfaces, from Molecular Dynamics Simulations. Langmuir, 2021, 37 (18), pp.5563-5572. 10.1021/acs.langmuir.1c00338 . hal-03354903

\section{HAL Id: hal-03354903 \\ https://hal.science/hal-03354903}

Submitted on 26 Sep 2021

HAL is a multi-disciplinary open access archive for the deposit and dissemination of scientific research documents, whether they are published or not. The documents may come from teaching and research institutions in France or abroad, or from public or private research centers.
L'archive ouverte pluridisciplinaire $\mathbf{H A L}$, est destinée au dépôt et à la diffusion de documents scientifiques de niveau recherche, publiés ou non, émanant des établissements d'enseignement et de recherche français ou étrangers, des laboratoires publics ou privés. 


\title{
Effects of the Chemical and Structural Properties
}

of Silane Monolayers on the Organization of Water

\author{
Molecules and Ions at Interfaces, from Molecular
}

\author{
Dynamics Simulations.
}

Solène Lecot ${ }^{\S}$, Antonin Lavigne ${ }^{\S}$, Zihua Yang ${ }^{\S}$, Yann Chevolot ${ }^{\S}$, Magali Phaner-Goutorbe ${ }^{\S}$, Christelle Yeromonahos ${ }^{\S *}$

$\S$ Université de Lyon, Institut des Nanotechnologies de Lyon UMR 5270, Ecole Centrale de Lyon, 36 avenue Guy de Collongue, 69134 Ecully, France

\section{* Corresponding Author}

Christelle Yeromonahos: christelle.yeromonahos@ec-lyon.fr, + 33472186235 


\begin{abstract}
Understanding the organization of the hydration layer at functionalized silica surfaces is relevant for a large range of biosensing applications or surface phenomena such as biomolecule adsorption. Silane monolayers are widely used to functionalize silica surfaces. Using Molecular Dynamics simulations, we have investigated the role of silane molecule head-group charge, alkyl chain length, and surface coverage, on the structural organization and dynamic properties of $\mathrm{Na}^{+}$ions, $\mathrm{Cl}^{-}$ions and water molecules at the interface. The silane molecules studied are 3aminopropyldimethylethoxysilane, n-propyldimethylmethoxysilane, octadecyldimethylmethoxysilane, and (dimethylamino)dimethylsilylundecanoate. Our results suggest that the distribution of interfacial ions is sensitive to the $2 \mathrm{D}$-dispersion of the silane charged head-groups. Also, while charged silane monolayers show a strong orientation of interfacial water molecules, that leads to a rupture in the hydrogen bond network and disturbs their tetrahedral organization, the arrangement of water molecules at the interface with uncharged silane monolayers seems to be related to the surface roughness and to alkyl chain length. In line with these results the diffusion of ions and water molecules is higher at the $\mathrm{CH}_{3}$ long monolayer interface than at the $\mathrm{CH}_{3}$ short monolayer interface, than at the charged monolayer interfaces. Also, whatever the silane molecules studied, bulk properties are recovered around $0.7 \mathrm{~nm}$ above the interface.
\end{abstract}

The interfacial water organization is known to impact biomolecule adsorption. So, these results could further help for optimizing the functionalization layers to capture analytes. 


\section{Introduction}

Recent publications have demonstrated that the hydration layer and its organization at solid interfaces plays a key role in several fundamental phenomena such as water wettability ${ }^{1,2}$ or biomolecule $\mathrm{e}^{3,4}$ adsorption. For example, Hegemann et al. have demonstrated that water molecules, confined inside a plasma polymer film, exhibit an amphiphilic subsurface gradient. This gradient is at the origin of long-range dipolar interactions governing the protein interactions with the surface. ${ }^{3}$ Other examples show that the hydration layer plays a decisive role in the adsorption of peptides ${ }^{4}$, proteins ${ }^{5}, \mathrm{DNA}^{6}$ or $\mathrm{RNA}^{7}$. Owing to the crucial role of the hydration layer, several authors have focused on understanding the effect of surface chemistry, and of surface structure, on the hydration layer..$^{8-21}$

Attenuated Total internal Reflection (ATR) Infrared spectroscopy, Second Harmonic Generation (SHG) spectroscopy, sum-frequency scattering and Molecular Dynamics (MD) simulations have revealed that water molecules orientation is influenced by the surface charge and that this orientation extends up to a few Angstroms above the interface. ${ }^{10-17}$ Chen et al. observed infrared spectroscopic evidence that a strongly hydrogen-bonded ordered network of water molecules is formed on hydrophilic $\mathrm{Si}-\mathrm{OH}$ surface contrary to hydrophobic $\mathrm{Si}-\mathrm{H}$ surface. ${ }^{18}$ On the contrary, several authors have proposed that water forms a highly ordered structure on hydrophobic surfaces which is at the origin of the entropically driven adsorption of protein by the disruption of this water ordered layer. ${ }^{5}$ The structure of the underlying layers were also evidenced to participate to interfacial water molecule organization. Indeed, while amorphous Poly(vinylidene fluoride) surfaces are less hydrophobic than the crystalline Poly(vinylidene fluoride) surfaces ${ }^{1}$, random distribution of butylthiols molecules on hydrophilic sphalerite surface results in a more hydrophobic surface than the one obtained with an ordered distribution ${ }^{2}$. MD simulations have demonstrated that the interaction strength between the hydration layer and noble metal surface $(\mathrm{Ag}, \mathrm{Au})$ varies as a function of the facets, 
typically, between $\mathrm{Au}(111)$ and ideal and reconstructed $\mathrm{Au}(100) .{ }^{19}$ Furthermore, the ions from the solution are also adsorbed on the interface and may also impact the hydration layer. ${ }^{20}$

Therefore, surface chemical modification may open the possibility of engineering the structure of the hydration layer. Silicon surface covered by $\mathrm{CH}_{3}$ and $\mathrm{CF}_{3}$ groups lead to a polygonal organization of water molecules that could persist up to $1 \mathrm{~nm}$ several nanometers above the interface, as suggested by MD simulations. ${ }^{21}$

Silane molecules are commercially available and are widely used for the surface chemical functionalization of oxides in particular $\mathrm{SiO}_{2}$. The structure, organization and surface energies of various silane layers have been investigated by various characterization techniques as a function of experimental parameters and silane structures. For example, long alkyl silane $n$ octadecyltricholorsilane (OTS) lead to well organized self-assembled monolayers while shorter 3 carbon $n$-propyltrichlorosilane gives rise to disordered layers. ${ }^{22,23}$ The end groups also influence the layer order. For example, the ester and cyanide counterpart of OTS lead to less ordered layers. ${ }^{24}$ However to the best of our knowledge, the impact of silane monolayer structure on the organization of the hydration layer has never been investigated.

In the present study, we investigate the effects of different silane monolayers, with different surface charges, alkyl chain lengths, and surface coverages, on the structural organization and diffusion of interfacial $\mathrm{Na}^{+}$ions, $\mathrm{Cl}^{-}$ions and water molecules. The four different silane molecules studied are 3-aminopropyldimethylethoxysilane (named $\mathrm{NH}_{3}{ }^{+}$), npropyldimethylmethoxysilane (named $\mathrm{CH}_{3}$ short), octadecyldimethylmethoxysilane (named $\mathrm{CH}_{3}$ long), and (dimethylamino)dimethylsilylundecanoate (named $\mathrm{COO}^{-}$). These systems were selected as we have previously studied their structure and organization. ${ }^{25}$ Herein, the distribution of ions, the ionic hydration structure, water molecule orientation and organization, and the diffusion of water molecules and ions at the interface with these different monolayers are deciphered by MD simulations. 


\section{Methods}

System description. Eleven different simulation systems were investigated, including one system without silane monolayer (bare $\mathrm{SiO}_{2}$ ) and ten systems with an amorphous $\mathrm{SiO}_{2}$ layer functionalized with different silane monolayers and different surface coverages, as summarized in Table 1. The systems were built using the method proposed by Roscioni et al. ${ }^{26}$ as described previously. ${ }^{25,27}$ Briefly, hydrolyzed silane molecules were initially randomly positioned on the $\mathrm{SiO}_{2}$ surface. No explicit bonding was used with the surface, allowing the spontaneous lateral organization of the silane molecules. The parameters of amorphous $\mathrm{SiO}_{2}$ surface were also taken from Roscioni et al. ${ }^{26}$ Approximately 20000 water molecules were randomly placed above the surface, as well as ions $\mathrm{Na}^{+}$and $\mathrm{Cl}^{-}$at a concentration of $0.2 \mathrm{M}$ each (i.e. $82 \mathrm{Na}^{+}$and $82 \mathrm{Cl}^{-}$ions). Furthermore, $\mathrm{Na}^{+}$or $\mathrm{Cl}^{-}$counter ions were added to compensate the head-group charges of silane molecules. To avoid interactions between water molecules and the bottom side of the $\mathrm{SiO}_{2}$ surface, a Lennard-Jones (LJ) wall was added at the top of the simulation box, whose dimensions are $7.8 \mathrm{~nm} \times 7.8 \mathrm{~nm} \times 15 \mathrm{~nm}$. The arrangement of silane molecules on the amorphous $\mathrm{SiO}_{2}$ layer, water molecules and ions are shown on Figure 1 and in Supporting information, Figure S1.

Table 1. Silane Monolayers and their Relative Surface Roughness

\begin{tabular}{|c|c|c|c|}
\hline $\begin{array}{c}\text { Silane } \\
\text { molecule }\end{array}$ & Silane structural formula & $\begin{array}{c}\text { Surface } \\
\text { coverage }\left(\mathrm{nm}^{-2}\right)\end{array}$ & $\begin{array}{l}\text { Relative surface } \\
\text { roughness a }\end{array}$ \\
\hline $\mathrm{CH}_{3}$ long & & $1.5-3.0-4.2$ & $1.0-0.92-0.42$ \\
\hline $\mathrm{CH}_{3}$ short & & $1.5-3.0-4.2$ & $0.49-0.41-0.27$ \\
\hline $\mathrm{NH}_{3}^{+}$ & & $3.0-4.2$ & $0.38-0.27$ \\
\hline $\mathrm{COO}^{-}$ & & $3.0-4.2$ & $0.55-0.26$ \\
\hline
\end{tabular}

${ }^{\mathrm{a}}$ The relative surface roughness is normalized to the value found for $\mathrm{CH}_{3}$ long at a coverage of $1.5 \mathrm{~nm}^{-2}$. The relative surface roughness for bare $\mathrm{SiO}_{2}$ is 0.22 . 

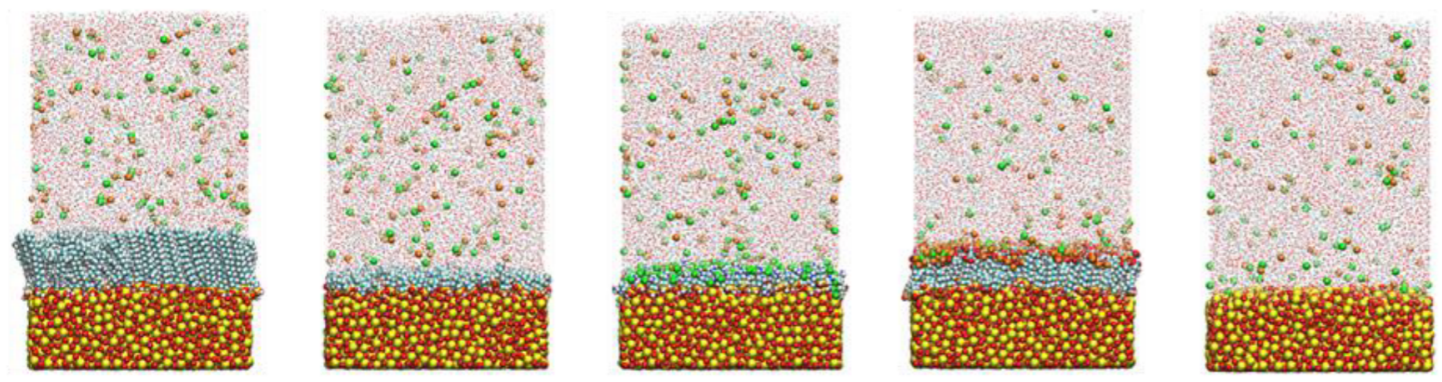

(a)
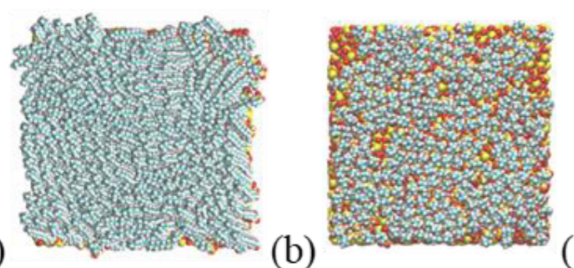

(b)

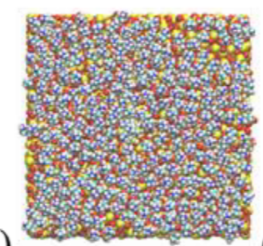

(c)

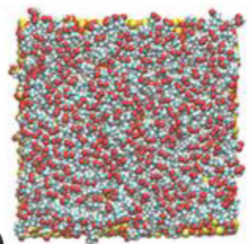

(d)

(e)

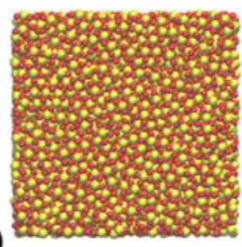

Figure 1. Arrangement of silane molecules, water and ions on the amorphous $\mathrm{SiO}_{2}$ layer (top) and top view of the surfaces (bottom) after $100 \mathrm{~ns}$ MD simulation for the systems: (a) $\mathrm{CH}_{3}$ long $\mathrm{c}=4.2 \mathrm{~nm}^{-2}$, (b) $\mathrm{CH}_{3}$ short $\mathrm{c}=4.2 \mathrm{~nm}^{-2}$, (c) $\mathrm{NH}_{3}{ }^{+} \mathrm{c}=4.2 \mathrm{~nm}^{-2}$, (d) $\mathrm{COO}^{-} \mathrm{c}=4.2 \mathrm{~nm}^{-2}$ and (e) bare $\mathrm{SiO}_{2}$. Atoms are shown in yellow (silicon), red (oxygen), cyan (carbon), white (hydrogen), blue (nitrogen), orange $\left(\mathrm{Na}^{+}\right)$and green $\left(\mathrm{Cl}^{-}\right)$. Water molecules are represented with points. Images of the simulations systems at $\mathrm{c}=3.0 \mathrm{~nm}^{-2}$ and $\mathrm{c}=1.5 \mathrm{~nm}^{-2}$ are shown in Supporting information, Figure S1.

Simulations details. Simulations were performed with the Gromacs software, version $5.1 .3,{ }^{28}$ while visualization was done with VMD, version $1.9 .3 .{ }^{29}$ After energy minimization using the steepest descent method, the system was equilibrated with NVT and NPT equilibrations of 100 ps each. Then, production simulations were performed for 100 ns. Integration of motion equations was performed using a leap-frog algorithm, with a time step of 2 fs. A LINCS algorithm was used to apply constraints to bond parameters. Temperature was kept at $300 \mathrm{~K}$

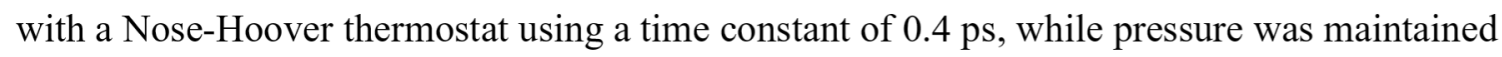
at 1 bar using a Parrinello-Rahman barostat and a time constant of 2 ps. As reported previously, ${ }^{25}$ the $\mathrm{SiO}_{2}$ layer and silane molecules were described with a force-field adapted 
from recent studies ${ }^{26,30}$ and from the OPLS all-atom force-field ${ }^{31}$. TIP4P water ${ }^{32}, \mathrm{Na}^{+}$ions ${ }^{33}$ and $\mathrm{Cl}^{-}$ions ${ }^{34}$ were described with the OPLS all-atom force-field, while parameters for the LJ wall were taken from a previous study ${ }^{1}$. Long range electrostatic interactions were calculated with the Particle Mesh Ewald method and a cut-off of $1 \mathrm{~nm}$. A cut-off distance of $1 \mathrm{~nm}$ was also used for LJ potentials.

Analysis parameters. The following parameters were investigated by using Gromacs analysis functions, VMD tools and home-made Python codes. Unless otherwise specified, the given values are averaged over the last $1 \mathrm{~ns}$ of the simulation.

Surface roughness. The surface roughness is evaluated at final state with a home-made Python code, by analogy with atomic force microscopy (AFM). Our methodology is adapted from Kong et al. ${ }^{35}$ The roughness is defined as the root-mean-square (RMS) deviation of the $z$-values accessible for square tip with size $0.4 \mathrm{~nm}$, scanning the surface in $x$ and $y$ directions with a minimal displacement of $0.15 \mathrm{~nm}$.

Radial distribution function and coordination number. The radial distribution functions (RDF) $g_{N a^{+}-O}(r), g_{N a^{+}-H}(r), g_{C l^{-}-O}(r)$, and $g_{C l^{-}-H}(r)$, and the corresponding coordination numbers $n_{\mathrm{Na}^{+}-\mathrm{O}}(r), n_{\mathrm{Na}^{+}-\mathrm{H}}(r), n_{C l^{-}-\mathrm{O}}(r)$, and $n_{C l^{-}-H}(r)$ give insight into the position and orientation of water molecules surrounding the $\mathrm{Na}^{+}$and $\mathrm{Cl}^{-}$ions. $g_{A-B}(r)$ is the probability of finding an atom of type $B$ at a distance $r$ from an atom of type $A$. The running corresponding coordination number $n_{A-B}(r)$, i.e. the number of atoms $B$ surrounding atom $A$ from 0 to $r$, is defined as: ${ }^{36}$

$$
n_{A-B}(r)=\frac{4 \pi N}{V} \int_{0}^{r} g_{A-B}(r) r^{2} d r
$$


where $N$ is the number of atoms of type $B$ and $V$ is the volume of the simulation cell. Furthermore, $n_{A-B}$ is the coordination number of the first solvation shell (i.e. for $r$ between 0 and the first minimum of the radial distribution function). ${ }^{37}$

Water dipole orientation. The orientation of water molecules is investigated by plotting the average cosine of the angle $\theta$ between the permanent dipole moment of the water molecule and the normal to the surface. A positive $\langle\cos \theta\rangle$ means that hydrogen atoms point outside the surface, while a negative $\langle\cos \theta\rangle$ means that hydrogen atoms point towards the surface.

Mean square displacement. The diffusion of water molecules and ions are investigated by calculating their mean squared displacement (MSD) over the last ns of the simulation.

\section{Results and Discussion}

\subsection{Distribution, ionic hydration structure, and diffusion of $\mathrm{Na}^{+}$and $\mathrm{Cl}^{-}$ions}

Distribution of ions. According to the Gouy-Chapman-Stern (GCS) model, in the presence of electrolytes $(\mathrm{NaCl}$ in the present study), the surface charge is balanced by the distribution of ions, which form three different layers above the surface. The first layer (the Helmholtz plane) is characterized by the specific adsorption of ions and oriented water molecules. At the outer of this plane, the second layer is characterized by the nonspecific adsorption of hydrated ions. These two layers form the compact Stern layer. At the outer of the Stern layer, the third layer (diffuse layer) is characterized by the nonspecific adsorption of hydrated ions at a concentration that gradually decreases towards the bulk water. ${ }^{15}$ The thickness of the diffuse layer is expected to increase as the concentration of ions decreases. For a concentration of $0.2 \mathrm{M}$ of $\mathrm{NaCl}$, the thickness of the diffuse layer (Debye length), is calculated to be $0.7 \mathrm{~nm}$ at $300 \mathrm{~K}$, while the thickness of the compact layer corresponds to a few water monolayers. However, several experimental and MD simulation studies have established the limitations of this model, as it

neglects ion-ion interactions. ${ }^{15,38-40}$ In particular, the composition of the compact layer and the 
thickness of the diffuse layer were shown to depend on the distribution of the negative charges on a surface. ${ }^{15}$ In the case of a uniform negative surface charge distribution, $\mathrm{Na}^{+}$specific adsorption is observed in the compact layer, while a gradual decrease in $\mathrm{Na}^{+}$concentration is observed in the diffuse layer as predicted by the GCS theory. However, in the case of localized negative surface charges, ion distribution varies with ion concentration. For $0.1 \mathrm{M}$ of $\mathrm{NaCl}, \mathrm{Na}^{+}$ ions are specifically adsorbed in the compact layer while no diffuse layer is observed. For the same localized negative surface charges and $0.5 \mathrm{M}$ of NaCl , a specific adsorption of $\mathrm{Na}^{+}$is still observed in the Helmholtz plane, but a depletion in $\mathrm{Na}^{+}$and a specific adsorption in $\mathrm{Cl}^{-}$are observed outer the Helmholtz plane in the compact layer, followed by a gradual $\mathrm{Na}^{+}$increase and a gradual $\mathrm{Cl}^{-}$decrease in the diffuse layer, whose thickness is smaller than the one predicted by the GCS model. ${ }^{15}$

Figure 1 illustrates the arrangement of all the silane monolayers studied on $\mathrm{SiO}_{2}$ surface, as well as the ion distributions, after 100 ns MD simulations. The distribution of ions along the surface normal is plotted in Figure 2 and in Supporting Information, Figure S2, for all the studied systems. In the case of the $\mathrm{NH}_{3}{ }^{+}$monolayer, as predicted by the GCS theory, a specific adsorption of $\mathrm{Cl}^{-}$ions is observed at the surface of the monolayer, followed by a diffuse layer, that spans over $\sim 0.7 \mathrm{~nm}$, in which the $\mathrm{Cl}^{-}$concentration decreases gradually. These results are in agreement with those obtained by Dewan et al. for a homogeneously spread surface charge. ${ }^{15}$ However, in the case of the $\mathrm{COO}^{-}$monolayer, the ion distributions are different. Indeed, in the compact layer, $\mathrm{Na}^{+}$ions are specifically adsorbed on the surface. An increase in the $\mathrm{Cl}^{-}$ions concentration is also observed near the surface. Above this compact layer, a $\sim 0.7 \mathrm{~nm}$ thick diffuse layer is observed, where the concentration of both $\mathrm{Na}^{+}$and $\mathrm{Cl}^{-}$is decreasing. Such adsorption of $\mathrm{Na}^{+}$and $\mathrm{Cl}^{-}$ions was observed by Dewan et al. for a localized surface charge distribution on $\mathrm{SiO}_{2}$ surfaces. ${ }^{15} \mathrm{So}$, the differences in ion distributions that we observe, on $\mathrm{NH}_{3}{ }^{+}$ and $\mathrm{COO}^{-}$monolayers, might be explained by the surface organization of the silane charged 
head-groups. Indeed, the head groups are more evenly dispersed on surface with $\mathrm{NH}_{3}{ }^{+}$silane molecules than with $\mathrm{COO}^{-}$silane molecules (Supporting Information, Figure S3). Also, our results suggest, in agreement with the study of Dewan et al., that an increase in $\mathrm{NH}_{3}{ }^{+}$or $\mathrm{COO}^{-}$ surface coverages does not lead to a significant increase in the thickness of the diffuse layer. For $\mathrm{CH}_{3}$ long and $\mathrm{CH}_{3}$ short monolayers, our results show that $\mathrm{Na}^{+}$and $\mathrm{Cl}^{-}$ions are, as expected, evenly dispersed in water. So, no compact layer neither diffuse layer is observed for these systems. However, an interfacial layer is defined, in which water density increases to reach the bulk value. The interfacial layer is about $0.7 \mathrm{~nm}$ thick and its origin is defined as the $z$ coordinate of the highest silane atom. In the case of the bare $\mathrm{SiO}_{2}$ surface, a slight increase in $\mathrm{Na}^{+}$concentration is observed, followed by a slight increase in $\mathrm{Cl}^{-}$concentration. Such distribution of ions could be explained by the partial charges of oxygen atoms despite the neutral global charge of our $\mathrm{SiO}_{2}$ surface.

(a)

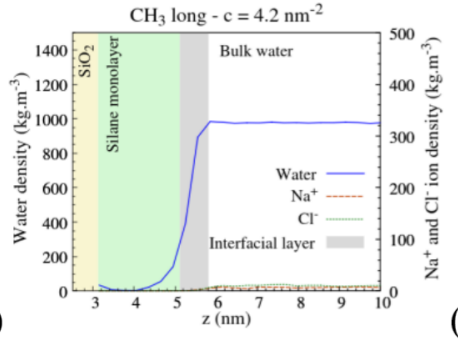

(b)

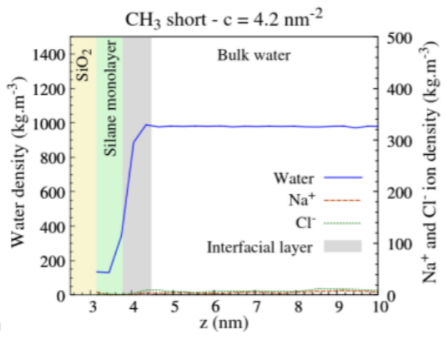

(c)

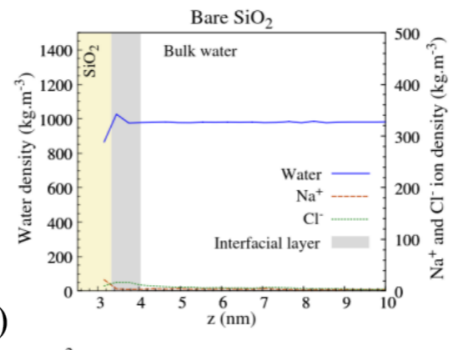

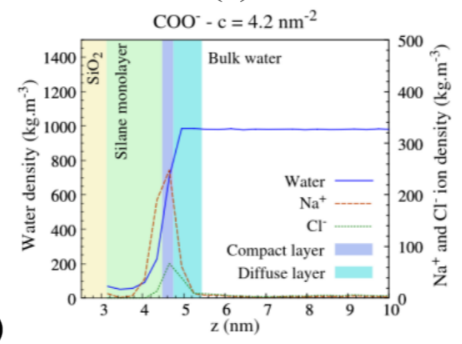

(e) (d)

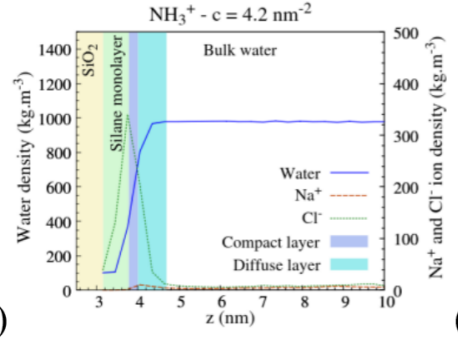

Figure 2. Distribution of water molecules, $\mathrm{Na}^{+}$ions and $\mathrm{Cl}^{-}$ions along the surface normal for the systems: (a) $\mathrm{CH}_{3}$ long $\mathrm{c}=4.2 \mathrm{~nm}^{-2}$, (b) $\mathrm{CH}_{3}$ short $\mathrm{c}=4.2 \mathrm{~nm}^{-2}$, (c) bare $\mathrm{SiO}_{2}$, (d) $\mathrm{NH}_{3}{ }^{+} \mathrm{c}=$ $4.2 \mathrm{~nm}^{-2}$ and (e) $\mathrm{COO}^{-} \mathrm{c}=4.2 \mathrm{~nm}^{-2}$. The compact and diffuse layers are represented for the systems $\mathrm{NH}_{3}{ }^{+}$and $\mathrm{COO}^{-}$and the $0.7 \mathrm{~nm}$ thick interfacial layer is shown for the systems $\mathrm{CH}_{3}$ 
long, $\mathrm{CH}_{3}$ short and bare $\mathrm{SiO}_{2}$. Figures for all other systems are shown in Supporting Information, Figure S2.

Ionic hydration structure and ion diffusion. The ionic hydration structures of $\mathrm{Na}^{+}$and $\mathrm{Cl}^{-}$ ions in the bulk water are the same whatever the system studied. The RDF in the bulk region of $\mathrm{NH}_{3}{ }^{+}$system at $\mathrm{c}=4.2 \mathrm{~nm}^{-2}$ and the corresponding coordination numbers are depicted in Figure 3. Similar curves are obtained for the bulk region in all the other systems and are shown in Supporting Information, Figures S4 and S5. Regarding the $\mathrm{Na}^{+}$ions, the first peak of $g_{N a^{+}-O}(r)$ is obtained at $2.4 \AA$ while the first peak of $g_{N a^{+}-H}(r)$ is located at $3.0 \AA$. Thus, water molecules are approaching the $\mathrm{Na}^{+}$ions with their oxygen atom. The coordination number, i.e. the number of water molecules in the first solvation shell of the ion, is calculated by integrating the RDF up to the first minimum, located at $3.2 \AA$ for $g_{\mathrm{Na}^{+}-\mathrm{O}}(r)$ and at $3.7 \AA$ for $g_{N a^{+}-H}(r)$. The coordination numbers are respectively 5.5 and 13.3. Regarding the $\mathrm{Cl}^{-}$ ions, the first peak of $g_{C l^{-}-H}(r)$ is obtained at $2.3 \AA$ and the first peak of $g_{C l^{-}-O}(r)$ at $3.2 \AA$. For $g_{C l^{-}-H}(r)$, a second peak is located at $3.6 \AA$, showing that only one hydrogen atom is pointing towards the $\mathrm{Cl}^{-}$ion. ${ }^{36}$ The coordination numbers are $n_{\mathrm{Cl}^{-}-\mathrm{O}}=6.7$ and $n_{\mathrm{Cl}^{-}-\mathrm{H}}=6.0$. All these results are in accordance with previous simulations studies of bulk water. ${ }^{36,37}$

(a)

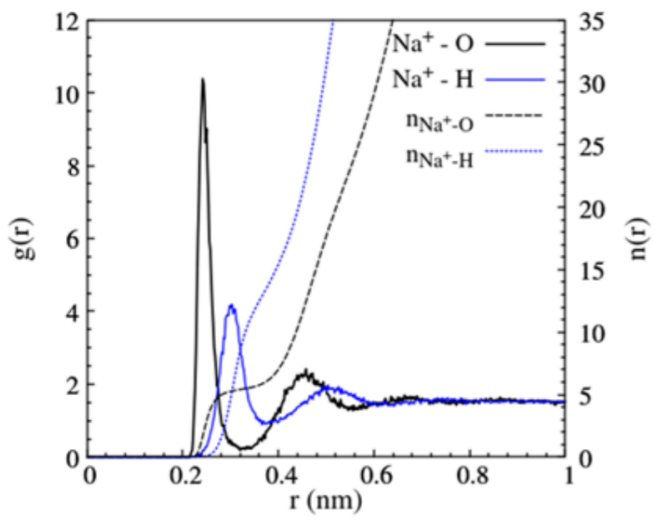

(b)

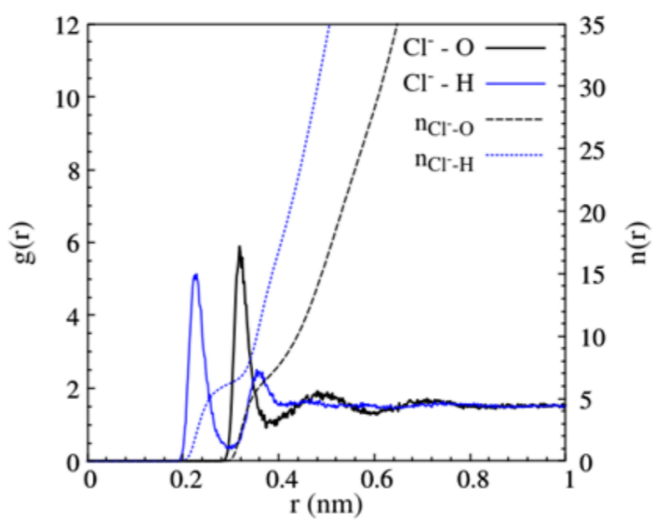

Figure 3. Typical radial distribution functions (solid lines) and corresponding coordination 
number (dotted lines) of (a) $\mathrm{Na}^{+}-\mathrm{O}$ and $\mathrm{Na}^{+}-\mathrm{H}$ and (b) $\mathrm{Cl}^{-}-\mathrm{O}$ and $\mathrm{Cl}^{-}-\mathrm{H}$ in the bulk region. Values are shown for the system $\mathrm{NH}_{3}{ }^{+} \mathrm{c}=4.2 \mathrm{~nm}^{-2}$, other values are given in Supporting Information, Figures S4 and S5.

The charged silane monolayers were shown to disturb the hydration structure of $\mathrm{Na}^{+}$and $\mathrm{Cl}^{-}$in the compact and diffuse layers. The coordination numbers $n_{\mathrm{Na}^{+}-\mathrm{O}}$ and $n_{\mathrm{Na}^{+}-\mathrm{H}}$ above the $\mathrm{COO}^{-}$ silane monolayers are given in Table 2 and in Supporting information, Figures S6 and S7, while $n_{\mathrm{Cl}^{-}-\mathrm{O}}$ and $n_{\mathrm{Cl}^{-}-\mathrm{H}}$ above the $\mathrm{NH}_{3}{ }^{+}$and $\mathrm{COO}^{-}$monolayers are summarized in Table 3 and in Supporting information, Figures S6 - S11. The coordination numbers are significantly lower in the compact layer than in the diffuse layer, and in the diffuse layer than in the bulk region. So, the charged monolayers involve a progressive depletion in the first solvation shell. This is in agreement with the results of Dewan et al. on a surface with localized negative charges ${ }^{15}$ and exhibits the role of both cations and anions in the water layer at the interface with the $\mathrm{COO}^{-}$ monolayers, which is not predicted by the Gouy-Chapman-Stern theory. Furthermore, our results suggest that the perturbation of the first solvation shell of the ions, in the compact and diffuse layers, increases as the silane surface coverage and the ion concentration increase. For instance, in the case of $\mathrm{NH}_{3}{ }^{+}$monolayers, $n_{C l^{-}-H}$ is equal to 6.0 in the bulk water, to 4.3 in the compact layer at $\mathrm{c}=3 \mathrm{~nm}^{-2}$ (while $\mathrm{Cl}^{-}$density is around $240 \mathrm{~kg} \cdot \mathrm{m}^{-3}$ ) and to 2.8 at $\mathrm{c}=4.2 \mathrm{~nm}^{-2}$ (while $\mathrm{Cl}^{-}$density is around $340 \mathrm{~kg} \cdot \mathrm{m}^{-3}$ ). The perturbation of the hydration structure of $\mathrm{Na}^{+}$and $\mathrm{Cl}^{-}$ions is in line with their diffusion coefficients (Figure 4, Table 4 and Supporting information Figure S12). Indeed, our results suggest that ion diffusion in the compact layers is significantly lower than in the diffuse layers and that ion diffusion in the diffuse layers is significantly lower than in the bulk water. In the case of $\mathrm{CH}_{3}$ long and $\mathrm{CH}_{3}$ short monolayers, the ion concentration in the interfacial layer is too low (because of the uniform distribution of ions in water) to allow the calculation of their hydration structure. 
Table 2. Coordination Numbers $n_{\mathrm{Na}^{+}-\mathrm{O}}$ and $\boldsymbol{n}_{\mathrm{Na}^{+}-\mathrm{H}}$ in the Different Water Layers of the Systems with $\mathrm{COO}^{-}$Silane Monolayers.

\begin{tabular}{ccccccc}
\hline \multirow{2}{*}{ Silane coverage } & \multicolumn{2}{c}{ Compact layer } & \multicolumn{2}{c}{ Diffuse layer } & \multicolumn{2}{c}{ Bulk water } \\
\cline { 2 - 7 } & $n_{\mathrm{Na}^{+}-\mathrm{O}^{\mathrm{a}}}$ & $n_{\mathrm{Na}^{+}-\mathrm{H}^{\mathrm{a}}}$ & $n_{\mathrm{Na}^{+}-\mathrm{O}}$ & $n_{\mathrm{Na}^{+}-\mathrm{H}}$ & $n_{\mathrm{Na}^{+}-\mathrm{O}}$ & $n_{\mathrm{Na}^{+}-\mathrm{H}}$ \\
\hline $\mathrm{c}=3.0 \mathrm{~nm}^{-2}$ & 3.5 & 10.2 & 4.4 & 11.9 & 5.5 & 13.3 \\
\hline $\mathrm{c}=4.2 \mathrm{~nm}^{-2}$ & 2.8 & 8.2 & 3.9 & 10.7 & 5.5 & 13.3 \\
\hline
\end{tabular}

${ }^{\mathrm{a}}$ The cut-off distance for the calculations of the coordination number is $3.2 \AA$ for $\mathrm{Na}-\mathrm{O}$ and $3.7 \AA$ for $\mathrm{Na}-\mathrm{H}^{36}$

Table 3. Coordination Numbers $n_{C l^{-}-o}$ and $n_{C l^{-}-H}$ in the Different Water Layers of the Systems with $\mathrm{COO}^{-}$and $\mathrm{NH}_{3}{ }^{+}$Silane Monolayers.

\begin{tabular}{lcccccc}
\hline \multirow{2}{*}{ Silane monolayer } & \multicolumn{2}{c}{ Compact layer } & \multicolumn{2}{c}{ Diffuse layer } & \multicolumn{2}{c}{ Bulk water } \\
\cline { 2 - 7 } & $n_{\mathrm{Cl}^{-}-\mathrm{O}^{\mathrm{a}}}$ & $n_{\mathrm{Cl}^{-}-\mathrm{H}^{\mathrm{a}}}$ & $n_{\mathrm{Cl}^{-}-\mathrm{O}}$ & $n_{\mathrm{Cl}^{-}-\mathrm{H}}$ & $n_{\mathrm{Cl}^{-}-\mathrm{O}}$ & $n_{\mathrm{Cl}^{-}-\mathrm{H}}$ \\
\hline $\mathrm{NH}_{3}{ }^{+} \mathrm{c}=3.0 \mathrm{~nm}^{-2}$ & 4.9 & 4.3 & 5.7 & 5.2 & 6.7 & 6.0 \\
\hline $\mathrm{NH}_{3}{ }^{+} \mathrm{c}=4.2 \mathrm{~nm}^{-2}$ & 3.5 & 2.8 & 5.6 & 5.0 & 6.8 & 6.1 \\
\hline $\mathrm{COO}^{-} \mathrm{c}=3.0 \mathrm{~nm}^{-2}$ & 5.0 & 2.6 & 6.0 & 4.6 & 6.8 & 6.2 \\
\hline $\mathrm{COO}^{-} \mathrm{c}=4.2 \mathrm{~nm}^{-2}$ & 4.0 & 1.6 & 5.1 & 3.0 & 6.9 & 6.3 \\
\hline
\end{tabular}

${ }^{\mathrm{a}}$ The cut-off distance for the calculations of the coordination number is $3.8 \AA$ for $\mathrm{Cl}-\mathrm{O}$ and $2.9 \AA$ for $\mathrm{Cl}-\mathrm{H}^{36}$

(a)

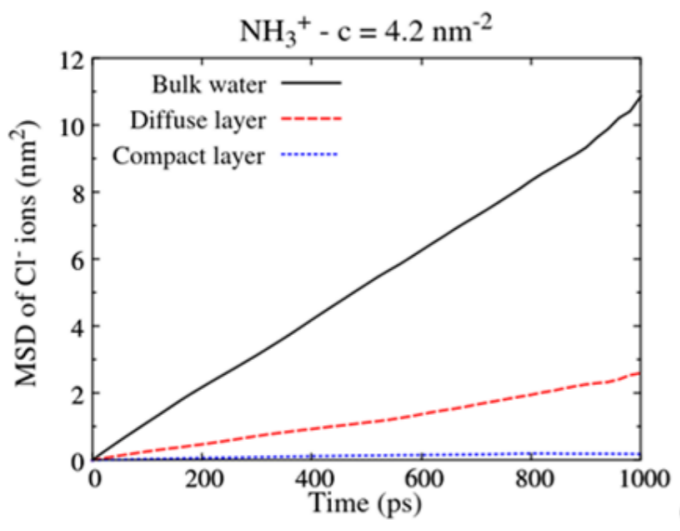

(b)

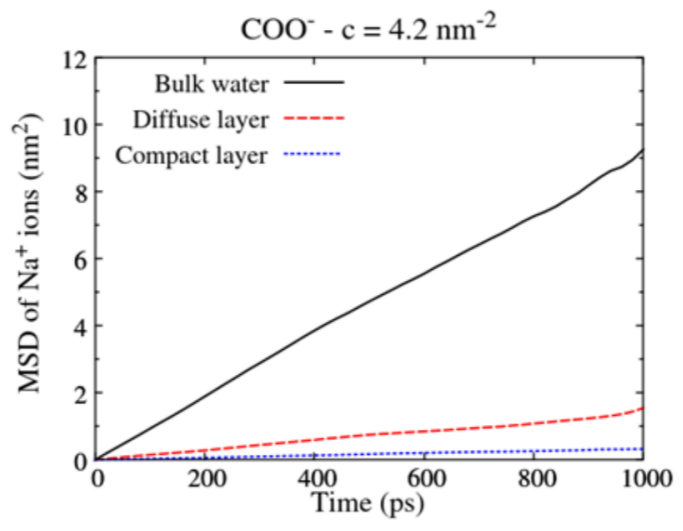

Figure 4. Mean square displacement in four different regions from the surface for (a) $\mathrm{Cl}^{-}$ions on the $\mathrm{NH}_{3}{ }^{+}$silane monolayer at $\mathrm{c}=4.2 \mathrm{~nm}^{-2}$ and (b) $\mathrm{Na}^{+}$ions on the $\mathrm{COO}^{-}$silane monolayer at $\mathrm{c}=4.2 \mathrm{~nm}^{-2}$. Values for both silane monolayers at $\mathrm{c}=3.0 \mathrm{~nm}^{-2}$ are given in Supporting Information, Figure S10. 
Table 4. Diffusion Coefficients of $\mathrm{Cl}^{-}$Ions Above $\mathrm{NH}_{3}{ }^{+}$Silane Monolayers and $\mathrm{Na}^{+}$Ions Above $\mathrm{COO}^{-}$Silane Monolayers.

\begin{tabular}{ccccc}
\hline \multirow{2}{*}{ Region } & \multicolumn{2}{c}{$\begin{array}{c}\text { Diffusion coefficient of } \mathrm{Cl}^{-} \text {ions } \\
\text { above } \mathrm{NH}_{3}{ }^{+} \text {monolayer }\left(\times 10^{5} \mathrm{~cm}^{2} . \mathrm{s}^{-1}\right)\end{array}$} & \multicolumn{2}{c}{$\begin{array}{c}\text { Diffusion coefficient of } \mathrm{Na}^{+} \text {ions } \\
\text { above COO monolayer }\left(\times 10^{5} \mathrm{~cm}^{2} . \mathrm{s}^{-1}\right)\end{array}$} \\
\cline { 2 - 5 } & $\mathrm{c}=3.0 \mathrm{~nm}^{-2}$ & $\mathrm{c}=4.2 \mathrm{~nm}^{-2}$ & $\mathrm{c}=3.0 \mathrm{~nm}^{-2}$ & $\mathrm{c}=4.2 \mathrm{~nm}^{-2}$ \\
\hline Compact layer & $0.10 \pm 0.02$ & $0.03 \pm 0.01$ & $0.11 \pm 0.03$ & $0.06 \pm 0.01$ \\
\hline Diffuse layer & $0.34 \pm 0.21$ & $0.41 \pm 0.11$ & $0.23 \pm 0.05$ & $0.22 \pm 0.06$ \\
\hline Bulk & $1.50 \pm 0.28$ & $1.71 \pm 0.01$ & $1.81 \pm 0.04$ & $1.49 \pm 0.21$ \\
\hline
\end{tabular}

\subsection{Arrangement and dynamics properties of water molecules}

Water orientation on the surface. We now investigate the arrangement of water molecules by deciphering the water dipole orientation (Figure 5 and Supporting information, Figure S13). In the bulk region, as expected, we observe that $\langle\cos \theta\rangle=0$ for all simulation systems, indicating that water molecules are randomly oriented and that there is no global dipole moment. Previous experimental ${ }^{10,11,41}$ and $\mathrm{MD}$ simulation ${ }^{15}$ studies have shown that, up to $1 \mathrm{~nm}$ above positively charged flat surfaces, water molecules are oriented with hydrogen atoms pointing outside the surface, while they are oriented with hydrogen atoms pointing towards the surface above negatively charged flat surfaces. Also, flat extended hydrophobic non-polar surfaces were shown to orient water molecules, up to $1 \mathrm{~nm}$ above the surface, with hydrogen atoms pointing towards the surface, ${ }^{16,17,42,43}$ while small hydrophobic solutes were shown to orient water molecules with hydrogen atoms pointing outside the surface. ${ }^{44}$ This organization results from the optimization of both the number of hydrogen bonds and the packing density of water molecules. ${ }^{43}$ 
(a)

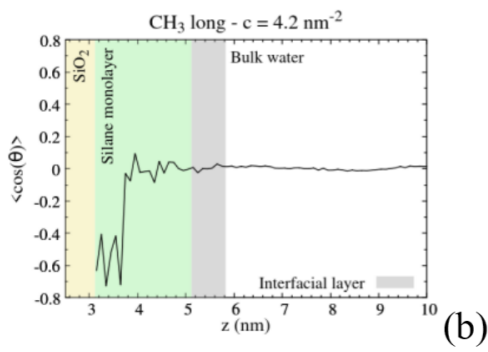

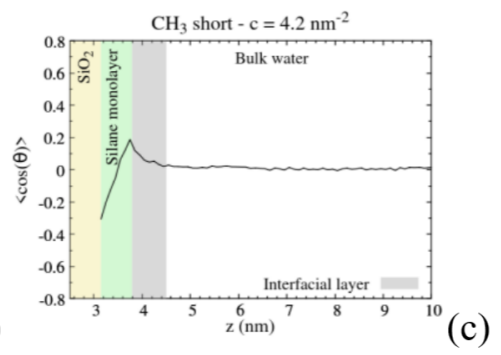
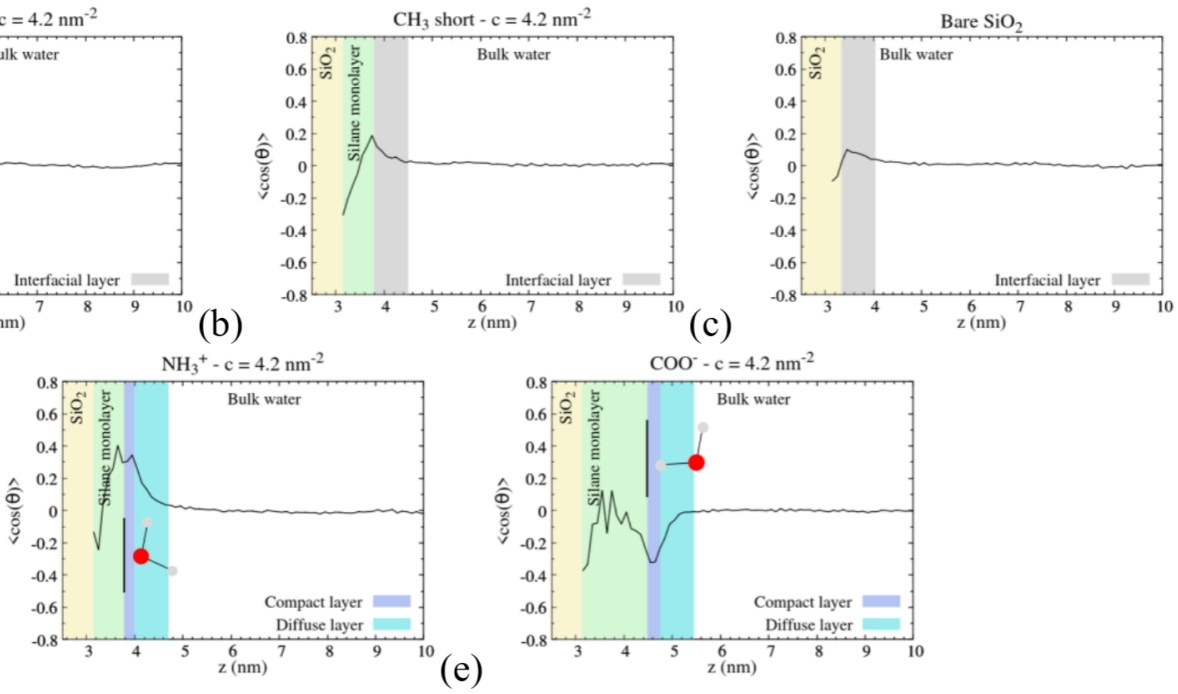

(d)

(e)

Figure 5. Effect of silane monolayers on water orientation ordering: $\langle\cos \theta\rangle$ water angle distribution along the normal to the $\mathrm{SiO}_{2}$ surface for the systems: (a) $\mathrm{CH}_{3}$ long $\mathrm{c}=4.2 \mathrm{~nm}^{-2}$, (b) $\mathrm{CH}_{3}$ short $\mathrm{c}=4.2 \mathrm{~nm}^{-2}$, (c) bare $\mathrm{SiO}_{2}$, (d) $\mathrm{NH}^{+} \mathrm{c}=4.2 \mathrm{~nm}^{-2}$ and (e) $\mathrm{COO}^{-} \mathrm{c}=4.2 \mathrm{~nm}^{-2}$. A water molecule is represented in the compact layer of $\mathrm{NH}_{3}{ }^{+}$and $\mathrm{COO}^{-}$systems. The compact and diffuse layers are represented for the systems $\mathrm{NH}_{3}{ }^{+}$and $\mathrm{COO}^{-}$and the $0.7 \mathrm{~nm}$ thick interfacial layer is shown for the systems $\mathrm{CH}_{3}$ long, $\mathrm{CH}_{3}$ short and $\mathrm{SiO}_{2}$. Figures for all other systems are shown in Supporting Information, Figure S13.

As depicted in Figure 5 and in Supporting information, Figure S13, our results show a positive $\langle\cos \theta\rangle$ for water molecules at the interface with $\mathrm{NH}_{3}{ }^{+}$silane monolayers, indicating that hydrogen atoms are pointing outside the surface. On the contrary, a negative $\langle\cos \theta\rangle$ is obtained at the interface with $\mathrm{COO}^{-}$silane monolayers, attesting that hydrogen atoms are pointing towards the surface. Furthermore, the strong global orientation of water molecules observed in the compact layer is gradually decreased in the diffuse layer. Contrary to previous results with flat negatively charged surfaces, ${ }^{15}$ we do not observe oscillations in the water orientation. It might be explained by the roughness of the silane monolayers (Table 1). 
Regarding the bare $\mathrm{SiO}_{2}$ surface, our results show that adsorbed water molecules slightly orient themselves with hydrogen atoms pointing towards the surface (negative $\langle\cos \theta\rangle$ ), while interfacial water molecules will preferentially orient themselves with hydrogen atoms pointing outside the surface (positive $\langle\cos \theta\rangle$ ). This result is consistent with a previous study ${ }^{15}$ and might be explained by the partial charges on oxygen and silicon atoms for adsorbed water molecules and by the adsorbed $\mathrm{Na}^{+}$ions for interfacial water.

At the interface with $\mathrm{CH}_{3}$ short monolayers, a positive $\langle\cos \theta\rangle$ is observed meaning that water molecules will preferentially orient themselves with hydrogen atoms pointing outside the surface. Also, the global orientation of water molecules is more pronounced as coverage increases. So, at the interface with $\mathrm{CH}_{3}$ short silane monolayer, water molecules orient themselves like at the vicinity of small hydrophobic solutes, ${ }^{44}$ and not like at the interface with a flat extended hydrophobic surface. ${ }^{16,17,42,43}$ Water molecules orient themselves in the vicinity of the methyl group independently from other silane molecules, which are well separated on the surface due to their short alkyl chains. Regarding the $\mathrm{CH}_{3}$ long monolayer, we do not observe any global orientation of water molecules at the interface $(\langle\cos \theta\rangle=0)$. This could be due to the higher surface roughness of $\mathrm{CH}_{3}$ long silane monolayers compared to $\mathrm{CH}_{3}$ short monolayers (Table 1), which is expected to prevent the formation of a global dipole field. ${ }^{43}$ It should be noted that the oscillations which are found within the $\mathrm{CH}_{3}$ long silane molecules at c $=4.2 \mathrm{~nm}^{-2}$ are due to the low water density in hydrophobic and densely packed silane monolayer (below $100 \mathrm{~kg} \cdot \mathrm{m}^{-3}$ ).

Furthermore, when the amorphous $\mathrm{SiO}_{2}$ layer is functionalized with a silane monolayer, a negative $\langle\cos \theta\rangle$ is systematically found near the $\mathrm{SiO}_{2}$ layer and persists along the alkyl chains within the silane layer. This result is consistent with a previous study that has established the possible orientation of water molecules confined inside carbon nanotubes. ${ }^{45}$ However, Nakumura et al. have shown that the direction of the global dipole moment of confined water 
depends on the diameter of the carbon nanotubes. ${ }^{45}$ So, the direction of the global dipole moment could be expected to depend on the type of silane molecule and silane coverage (i.e. to depend on the distance between silane molecules). Nevertheless, the same negative direction is obtained whatever the coverage. So, our results suggest that the orientation of the global dipole moment is determined more by the $\mathrm{SiO}_{2}$ surface, which induces an initial negative orientation, than by the distance between silane molecules.

Water molecule organization. In the absence of dipole field, and if the inter-molecular distance is below $5 \AA$, water molecules can organize themselves into a tetrahedral network due to hydrogen-bond interactions. ${ }^{3}$ In crystalline ice, a well-defined tetrahedral network appears, while in bulk water only a short-range order remains. ${ }^{46}$ Also, from the analysis of the water water angle distribution, water molecules in the vicinity of hydrophobic surfaces were shown to exhibit a higher order than in the bulk. ${ }^{46}$ More information on the hydrogen bond network is given by the balance between accepting and donating hydrogen bonds. Indeed, while a global balance is expected between hydrogen bond donors and acceptors in bulk liquid water, it can be disrupted at an interface. ${ }^{12}$

The short-range structure of water molecules can be evaluated through the radial distribution function $g_{0-o}(r)$, which shows a first peak located at $2.8 \AA$, and the corresponding coordination number $n_{O-o}$. Furthermore, information on hydrogen bonding environment is given by $g_{O-H}(r)$ and $g_{H-O}(r)$. Indeed, the first peak of $g_{O-H}(r)$ is located at $1.0 \AA$ and corresponds to the intramolecular covalent $\mathrm{O}-\mathrm{H}$ bond while a second peak appears at $1.7-1.8$ $\AA$ and is related to hydrogen bonding. ${ }^{36}$ More precisely, this second peak is related to hydrogen bonds donors, while the second peak in the $g_{H-O}(r)$ shows hydrogen bond acceptors. Thus, the balance between accepting and donating hydrogen bonds is given by $\mathrm{nb}_{\text {Acceptors }}$ $\mathrm{nb}_{\text {Donors }}=2 n_{H-O}\left(r_{\min }^{2 \text { nd peak }}\right)-n_{O-H}\left(r_{\min }^{2 \text { nd peak }}\right), \quad$ where $\quad n_{A-B}\left(r_{\min }^{2 n d \text { peak }}\right) \quad$ is the coordination number obtained at the second minimum of the radial distribution function 
$g_{A-B}(r)$. Typical radial distribution functions $g_{O-O}(r), g_{O-H}(r)$ and $g_{H-O}(r)$ in bulk water and corresponding coordination numbers are shown in Supporting information, Figure S14. The evolution of $n_{O-O}$ and $\mathrm{nb}_{\text {Acceptors }}-\mathrm{nb}_{\text {Donors }}$ along the surface normal are depicted in Figure 6 and in Supporting information, Figure S15.

(a)

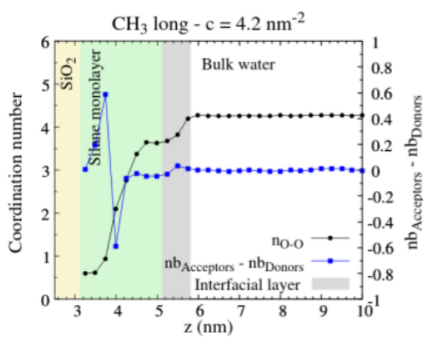

(b)

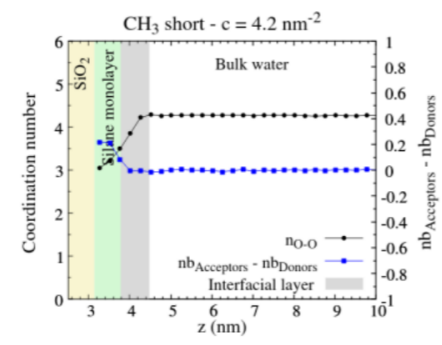

(c)

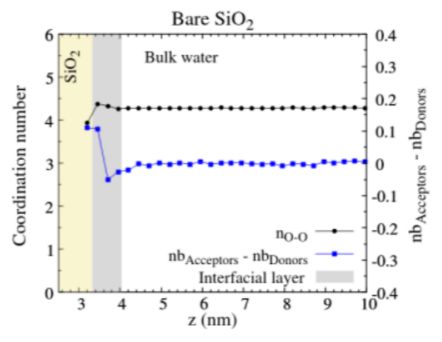

(d)

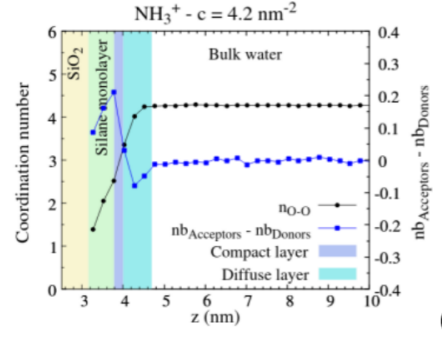

(e)

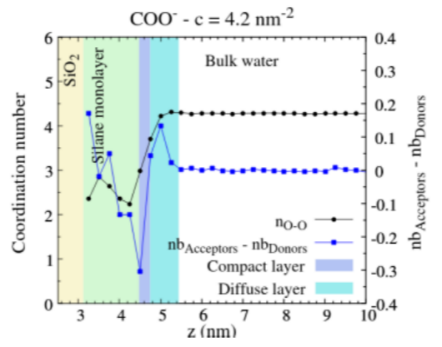

Figure 6. Evolution of the coordination number of water molecule and balance between acceptors and donors in hydrogen bonds along the normal to the surface for the systems: (a) $\mathrm{CH}_{3}$ long $\mathrm{c}=4.2 \mathrm{~nm}^{-2}$, (b) $\mathrm{CH}_{3}$ short $\mathrm{c}=4.2 \mathrm{~nm}^{-2}$, (c) bare $\mathrm{SiO}_{2}$, (d) $\mathrm{NH}^{+} \mathrm{c}=4.2 \mathrm{~nm}^{-2}$ and (e) $\mathrm{COO}^{-} \mathrm{c}=4.2 \mathrm{~nm}^{-2}$. The compact and diffuse layers are represented for the systems $\mathrm{NH}_{3}{ }^{+}$ and $\mathrm{COO}^{-}$and the $0.7 \mathrm{~nm}$ thick interfacial layer is shown for the systems $\mathrm{CH}_{3}$ long, $\mathrm{CH}_{3}$ short and $\mathrm{SiO}_{2}$. The cut-off distance for the calculations of the O-O coordination number is $3.3 \AA^{36}$ and the cut-off distance for $\mathrm{O}-\mathrm{H}$ and $\mathrm{H}-\mathrm{O}$ coordination numbers is $2.5 \AA$. Figures for all other systems are shown in Supporting Information, Figure S15.

In the bulk region, our results show that, for all the simulation systems, the coordination number $n_{O-O}$ is about 4.3 , as expected for a tetrahedral network. Also, the number of donating and accepting hydrogen bonds are equal, indicating that water molecules are randomly oriented and that there is no rupture in the hydrogen bond network. In agreement with these results, we 
observe that the water diffusion in the bulk region is the same for all the simulation systems (Supporting information, Figure S16). The diffusion coefficient is in the range $3.3-3.4 \times 10^{-5}$ $\mathrm{cm}^{2} . \mathrm{s}^{-1}$, close to the value of $3.55 \times 10^{-5} \mathrm{~cm}^{2} . \mathrm{s}^{-1}$ found by Yang et $\mathrm{al}^{47}$

However, in the vicinity of the silane monolayers, the coordination number $n_{O-O}$ is decreased, in agreement with the study of Yang et al., ${ }^{47}$ indicating that the first solvation shell of water molecules is disrupted by the silane molecules, and that the tetrahedral water network is disturbed. In the case of $\mathrm{NH}_{3}{ }^{+}$and $\mathrm{COO}^{-}$silane monolayers, $n_{O-O}$ is about 2.5 in the compact layer and increases in the diffuse layer to reach the bulk value of 4.3. These results can be explained by the strong orientation of water molecules in these layers and are in line with the unbalance obtained between the number of accepting and donating hydrogen bonds. In the case of $\mathrm{CH}_{3}$ short and $\mathrm{CH}_{3}$ long monolayers, the first solvation shell is only slightly disturbed as $n_{O-O}$ is about 3.5 in the interfacial layer. This result can be explained by the low global orientation of water molecules and by the balance obtained between the number of donating and accepting hydrogen bonds. These results are in line with the diffusion coefficients of water molecules which are, as expected, ${ }^{21,48}$ higher in the interfacial layers of $\mathrm{CH}_{3}$ short and $\mathrm{CH}_{3}$ long systems than in the compact layers of $\mathrm{NH}_{3}{ }^{+}$and $\mathrm{COO}^{-}$systems (Figure 7 and Supporting information, Figure S17). Furthermore, water diffusivity increases with increasing coverage, since hydrophobicity is also increased (Figure 8 and Supporting information, Figure S18).

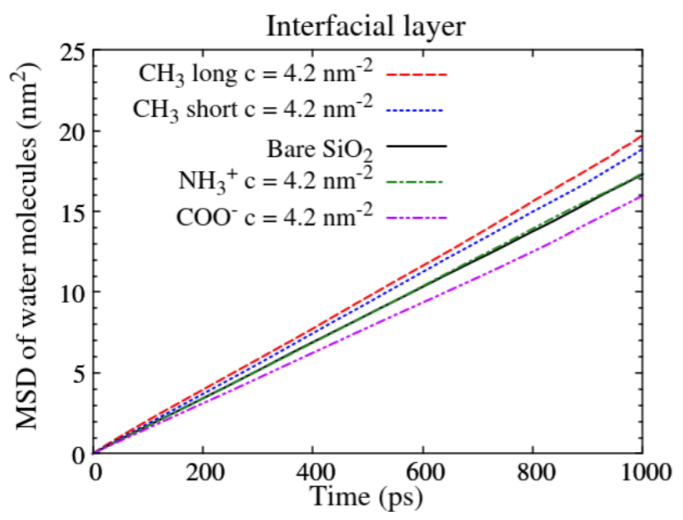


Figure 7. Mean square displacement of interfacial water molecules above the bare $\mathrm{SiO}_{2}$ layer and silane monolayers $\mathrm{CH}_{3}$ long, $\mathrm{CH}_{3}$ short, $\mathrm{NH}_{3}{ }^{+}$and $\mathrm{COO}^{-}$at coverage $\mathrm{c}=4.2 \mathrm{~nm}^{-2}$. For $\mathrm{NH}_{3}{ }^{+}$and $\mathrm{COO}^{-}$silane monolayer, interfacial water includes molecules from both the compact layer and the diffuse layer. Values at coverages $\mathrm{c}=3.0 \mathrm{~nm}^{-2}$ and $\mathrm{c}=1.5 \mathrm{~nm}^{-2}$ are shown in Supporting Information, Figure S17.

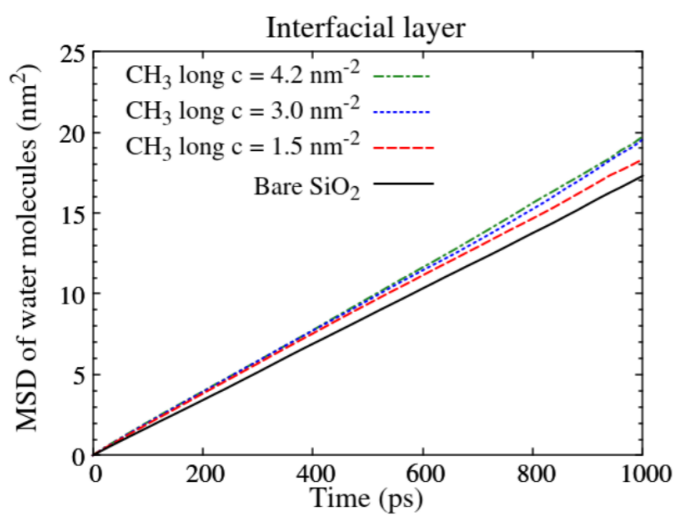

Figure 8. Mean square displacement of interfacial water molecules above the bare $\mathrm{SiO}_{2}$ layer and $\mathrm{CH}_{3}$ long silane monolayer at different coverages. Values for $\mathrm{CH}_{3}$ short monolayer are given in Supporting Information, Figure S18.

\section{Conclusions}

The organization and the dynamics properties of interfacial $\mathrm{Na}^{+}$ions, $\mathrm{Cl}^{-}$ions and water molecules are shown to depend on the structure of the silane monolayer and on the charge of the silane molecule head-groups.

Indeed, our results suggest that the ion distribution at the interface with the silane monolayers is sensitive to the spatial distribution of the charged silane head-groups. The more evenly dispersed silane molecules $\left(\mathrm{NH}_{3}{ }^{+}\right.$silanes) lead to a distribution of $\mathrm{Cl}^{-}$ions that follows the GCS model, while in the case of monolayers with higher degree of aggregation ( $\mathrm{COO}^{-}$silanes) two specific layers of ions $\left(\mathrm{Na}^{+}\right.$followed by $\left.\mathrm{Cl}^{-}\right)$are observed at the interface. Furthermore, a strong global orientation of water molecules is observed at the interface with charged silane 
monolayers, leading to a disruption in the first solvation shell of ions, a disruption in the tetrahedral organization of water molecules, and a rupture in the balance between accepting and donating hydrogen bonds. In line with these results, the diffusivity of ions and water molecules is reduced near charged silane monolayers, compared to the bare $\mathrm{SiO}_{2}$ surface.

Regarding the uncharged $\mathrm{CH}_{3}$ long and $\mathrm{CH}_{3}$ short silane monolayers, our results suggest that the arrangement of interfacial water molecules is related to the surface roughness. Indeed, no global orientation of water molecules is observed at the interface with the $\mathrm{CH}_{3}$ long silane monolayers whereas a slight global orientation of interfacial water molecules is obtained with the $\mathrm{CH}_{3}$ short monolayers. These results could be explained by the higher roughness of the $\mathrm{CH}_{3}$ long monolayers and by the 2D-dispersion of the methyl groups of $\mathrm{CH}_{3}$ short silane molecules due to their short alkyl chains. Indeed, in the vicinity of the methyl groups of the $\mathrm{CH}_{3}$ short monolayers, water molecules orient themselves with hydrogen atoms pointing outside the surface, as already reported around small hydrophobic solutes. In line with these results, the tetrahedral organization of water molecules and the balance between the donating and accepting hydrogen bonds are higher at the $\mathrm{CH}_{3}$ long and $\mathrm{CH}_{3}$ short monolayer interfaces than at charged monolayer interfaces. Also, the diffusivity of ions and water molecules is higher at the $\mathrm{CH}_{3}$ long monolayer interface than at the $\mathrm{CH}_{3}$ short monolayer interface, than at charged monolayers interfaces.

Finally, whatever the system studied, the bulk properties are recovered $\sim 0.7 \mathrm{~nm}$ above the silane monolayer.

The structural organization and dynamic properties of interfacial water molecules and ions could impact biomolecule adsorption. So, these results could further help for optimizing the surface chemical functionalization layers to capture analytes or to prevent nonspecific adhesion. 


\section{ASSOCIATED CONTENT}

The following files are available free of charge.

Arrangement of simulation systems at surface coverages $\mathrm{c}=1.5 \mathrm{~nm}^{-2}$ and $\mathrm{c}=3.0 \mathrm{~nm}^{-2}$. Water and ions distributions with silane monolayers at $\mathrm{c}=1.5 \mathrm{~nm}^{-2}$ and $\mathrm{c}=3.0 \mathrm{~nm}^{-2}$. In-plane distribution of silane molecule head-group charges. Ionic hydration structure in bulk water. Hydration structure of ions adsorbed on charged surfaces. Ion diffusion near the charged surfaces. Water orientation near the surface. Water structure near the surface. Diffusion of water molecules. (PDF)

\section{AUTHOR INFORMATION}

\section{Corresponding Author}

*Email: christelle.yeromonahos@ec-lyon.fr

\section{Author Contributions}

The manuscript was written through contributions of all authors. All authors have given approval to the final version of the manuscript.

\section{Funding Sources}

This work was supported by the Young Researcher ANR PORIDG project, grant ANR-18CE09-0006 of the French Agence Nationale de la Recherche. This work was granted access to the HPC resources of CINES under the allocation 2019-A0070711100 made by GENCI. Also, this work was supported by the PMCS2I - supercomputer Newton from Ecole Centrale de Lyon, France, member of the FLMSN.

\section{ACKNOWLEDGMENT}


The authors thank Laurent Pouilloux, Anne Cadiou, and Laurent Carrel for support on PMCS2I resources. S. L. is grateful to the "doctoral school Material" from the University of Lyon, France, for offering a Ph.D. fellowship. A. L. is grateful to the ANR PORIDG, of the French Agence Nationale de la Recherche, for funding his Ph.D. fellowship. Z. Y. is grateful to the China Scholarship Council.

\section{REFERENCES}

(1) Kitabata, M.; Taddese, T.; Okazaki, S. Molecular Dynamics Study on Wettability of Poly (vinylidene fluoride) Crystalline and Amorphous Surfaces. Langmuir 2018, 34, 12214-12223.

(2) Anvari, M. H.; Liu, Q.; Xu, Z.; Choi, P. Molecular Dynamics Study of Hydrophilic Sphalerite (110) Surface as Modified by Normal and Branched Butylthiols. Langmuir 2018, 34, $3363-3373$

(3) Hegemann, D.; Hocquard, N.; Heuberger, M. Nanoconfined Water Can Orient and Cause Long-Range Dipolar Interactions with Biomolecules. Sci. Rep. 2017, 7, 17852.

(4) Skelton, A. A.; Liang, T.; Walsh, T. R. Interplay of Sequence, Conformation, and Binding at the Peptide-Titania Interface as Mediated by Water. ACS Appl. Mater. Interfaces 2009, 1, $1482-1491$.

(5) Haynes, C. A.; Sliwinsky, E.; Norde, W. Structural and Electrostatic Properties of Globular Proteins at a Polystyrene-Water Interface. J. Colloid Interface Sci. 1994, 164, 394-409.

(6) Rosa, M.; Di Felice, R.; Corni, S. Adsorption Mechanisms of Nucleobases on the Hydrated Au(111) Surface. Langmuir 2018, 34, 14749-14756.

(7) Ruan, M.; Seydou, M.; Noel, V.; Piro, B.; Maurel, F.; Barbault, F. Molecular Dynamics Simulation of a RNA Aptasensor. J. Phys. Chem. B 2017, 121, 4071-4080. 
(8) Sacquin-Mora, S.; Fuchs, A.H.; Schoen, M. Torsion-Induced Phase Transitions in Fluids Confined Between Chemically Decorated Substrates. J. Chem. Phys. 2004, 121, 9077-9086.

(9) Pham, T. T.; Jonchère, A.; Dufrêche, J. F.; Brevet, P. F.; Diat, O. Analysis of the Second Harmonic Generation Signal from a Liquid / Air and Liquid / Liquid Interface. J. Chem. Phys. 2017, 146, 144701.

(10) Anim-Danso, E. ; Zhang, Y. ; Dhinojwala, A. Surface Charge Affects the Structure of Interfacial Ice. J. Phys. Chem. C. 2016, 120, 3741-3748.

(11) Nihonyanagi, S.; Yamaguchi, S.; Tahara, T. Direct Evidence for Orientational Flip-flop of Water Molecules at Charged Interfaces: A Heterodyne-Detected Vibrational Sum Frequency Generation Study. J. Chem. Phys. 2009, 130, 204704.

(12) Vácha, R.; Rick, S.W.; Jungwirth, P.; de Beer, A.G.F.; de Aguiar, H.B.; Samson, J.S.; Roke, S. The Orientation and Charge of Water at the Hydrophobic Oil Droplet Water Interface. J. Am. Chem. Soc. 2011, 133, 10204-10210.

(13) Strazdaite, S.; Versluis, J.; Bakker, H. J. Water Orientation at Hydrophobic Interfaces. $J$. Chem. Phys. 2015, 143, 084708.

(14) Tyrode, E.; Liljeblad, J. F. D. Water Structure Next to Ordered and Disordered Hydrophobic Silane Monolayers: A Vibrational Sum Frequency Spectroscopy Study. J. Phys. Chem. C 2013, 117, 1780-1790.

(15) Dewan, S.; Carnevale, V.; Bankura, A.; Eftekhari-Bafrooei, A.; Fiorin, G.; Klein, M. L.; Borguet, E. Structure of Water at Charged Interfaces: A Molecular Dynamics Study. Langmuir 2014, 30, 8056-8065.

(16) Jena, K. C.; Hore, D. K. Water Structure at Solid Surfaces and its Implications for Biomolecule Adsorption. Phys. Chem. Chem. Phys. 2010, 12, 14383-14404. 
(17) Schnupf, U.; Brady, J. W. Water Structuring above Solutes with Planar Hydrophobic Surfaces. Phys. Chem. Chem. Phys. 2017, 19, 11851-11863.

(18) Chen, L.; He, X.; Liu, H.; Qian, L.; Kim, S. H. Water Adsorption on Hydrophilic and Hydrophobic Surfaces of Silicon. J. Phys. Chem. C 2018, 122, 11385-11391.

(19) Hughes, Z. E.; Wright, L. B.; Walsh, T. R. Biomolecular Adsorption at Aqueous Silver Interfaces: First-Principles Calculations, Polarizable Force-Field Simulations, and Comparisons with Gold. Langmuir 2013, 29, 13217-13229.

(20) Adapa, S.; Swamy, D. R.; Kancharla, S.; Pradhan, S.; Malani, A. Role of Mono- and Divalent Surface Cations on the Structure and Adsorption Behavior of Water on Mica Surface. Langmuir 2018, 34, 14472-14488.

(21) Lee, D.; Schwegler, E.; Kanai, Y. Dependence of Water Dynamics on Molecular Adsorbates near Hydrophobic Surfaces: First-Principles Molecular Dynamics Study. J. Phys. Chem. C 2014, 118, 16, 8508-8513.

(22) Bierbaum, K.; Kinzler, M.; Woll, Ch.; Grunze, M.; Hahner, G.; Heid, S.; Effenberger, F. A Near Edge X-ray Absorption Fine Structure Spectroscopy and X-Ray Photoelectron Spectroscopy Study of the Film Properties of Self-Assembled Monolayers of Organosilanes on Oxidized Si(100). Langmuir 1995, 11, 512-518.

(23) Bierbaum, K.; Grunze, M.; Baski, A. A.; Chi, L. F.; Schrepp, W.; Fuchs, H. Growth of Self-Assembled n-Alkyltrichlorosilane Films on $\mathrm{Si}(100)$ Investigated by Atomic Force Microscopy. Langmuir 1995, 11, 2143-2150.

(24) Vallant, T.; Kattner, J.; Brunner, H.; Mayer, U.; Hoffmann, H. Investigation of the Formation and Structure of Self-Assembled Alkylsiloxane Monolayers on Silicon Using In Situ Attenuated Total Reflection Infrared Spectroscopy. Langmuir 1999, 15, 5339-5346. 
(25) Lecot, S.; Lavigne, A.; Yang, Z.; Géhin, T.; Botella, C.; Jousseaume, V.; Chevolot, Y.; Phaner-Goutorbe, M.; Yeromonahos, C. Arrangement of Monofunctional Silane Molecules on Silica Surfaces: Influence of the Alkyl Chain Length, Head-Group Charge and Surface Coverage, from Molecular Dynamics Simulations, X-Ray Photoelectron Spectroscopy and Fourier Transform Infrared Spectroscopy Analysis. J. Phys. Chem. C 2020, 124, 20125-20134.

(26) Roscioni, O. M.; Muccioli, L.; Mityashin, A.; Cornil, J.; Zannoni, C. Structural Characterization of Alkylsilane and Fluoroalkylsilane Self-Assembled Monolayers on $\mathrm{SiO} 2$ by Molecular Dynamics Simulations. J. Phys. Chem. C 2016, 120, 14652-14662.

(27) Lecot, S.; Chevolot, Y.; Phaner-Goutorbe, M.; Yeromonahos, C. Impact of Silane Monolayers on the Adsorption of Streptavidin on Silica and its Subsequent Interactions with Biotin: Molecular Dynamics and Steered Molecular Dynamics Simulations. J. Phys. Chem. B 2020, $124,6786-6796$.

(28) Van Der Spoel, D.; Lindahl, E.; Hess, B., Groenhof, G.; Mark, A. E.; Berendsen, H. J. GROMACS: Fast, Flexible, and Free. J. Comput. Chem. 2005, 26, 1701-1718.

(29) Humphrey, W.; Dalke, A.; Schulten, K. VMD: Visual Molecular Dynamics. J. Mol. Graph. 1996, 14, 33-38.

(30) Castillo, J. M.; Klos, M.; Jacobs, K.; Horsch, M.; Hasse, H. (2015). Characterization of Alkylsilane Self-Assembled Monolayers by Molecular Simulation. Langmuir 2015, 31, 26302638.

(31) Jorgensen, W. L.; Gao, J. Monte Carlo Simulations of the Hydration of Ammonium and Carboxylate Ions. J. Phys. Chem. 1986, 90, 2174-2182.

(32) Jorgensen, W. L., Chandrasekhar, J.; Madura, J. D. Comparison of Simple Potential Functions for Simulating Liquid Water. J. Chem. Phys. 1983, 79, 926-935. 
(33) Aqvist, J. Ion-Water Interaction Potentials Derived from Free Energy Perturbation Simulations. J. Phys. Chem. 1990, 94, 8021-8024.

(34) Chandrasekhar, J.; Spellmeyer, D. C.; Jorgensen, W.L. Energy Component Analysis for Dilute Aqueous Solutions of Lithium (1+), Sodium (1+), Fluoride (1-), and Chloride (1-) Ions. J. Am. Chem. Soc. 1984, 106, 903-910.

(35) Kong, Z.; Wang, Q.; Chen, E.; Wu, T. Study on Preparation Method for Short-Chain Alkylsiloxane Self-Assembled Monolayers and the Diffusion Behavior of Cooper on Silica Surfaces. Appl. Surf. Sci. 2013, 279, 171-179.

(36) Bankura, A.; Carnevale, V.; Klein, M. L. Hydration Structure of Salt Solutions from $A b$ Initio Molecular Dynamics. J. Chem. Phys. 2013, 138, 014501.

(37) Zhou, J.; Lu, X.; Wang, Y.; Shi, J. Molecular Dynamics Study on Ionic Hydration. Fluid Phase Equilib. 2002, 194, 257-270.

(38) Eftekhari-Bafrooei, A.; Borguet, E. Effect of electric fields on the ultrafast vibrational relaxation of water at a charged solid/liquid interface as probed by vibrational sum frequency generation. J. Phys. Chem. Lett. 2011, 2, 1353-1358.

(39) Zhang, H.; Hassanali, A. A.; Shin, Y. K.; Knight, C.; Singer, S. J. The water-amorphous silica interface: Analysis of the Stern layer and surface conduction. J. Chem. Phys. 2011, 134, 024705 .

(40) Marry, V.; Rotenberg, B.; Turq, P. Structure and dynamics of water at a clay surface from molecular dynamics simulation. Phys. Chem. Chem. Phys. 2008, 10, 4802-4813.

(41) Ye, S.; Nihonyanagi, S.; Uosaki, K. Sum Frequency Generation (SFG) Study of the pHDependent Water Structure on a Fused Quartz Surface Modified by an Octadecyltrichlorosilane (OTS) Monolayer. Phys. Chem. Chem. Phys. 2001, 3, 3463-3469. 
(42) Argyris, D.; Tummala, N. R.; Striolo, A.; Cole, D. R. Molecular Structure and Dynamics in Thin Water Films at the Silica and Graphite Surfaces. J. Phys. Chem. C 2008, 112, 13587 13599.

(43) Lee, C. Y.; McCammon, J. A.; Rossky, P. J. The Structure of Liquid Water at an Extended Hydrophobic Surface. J. Chem. Phys. 1984, 80, 4448.

(44) Rossky, P. J.; Karplus, M. Solvation. A Molecular Dynamics Study of a Dipeptide in Water. J. Am. Chem. Soc. 1979, 101, 1913-1937.

(45) Nakamura, Y.; Ohno, T. Ferroelectric Mobile Water. Phys. Chem. Chem. Phys. 2011, 13, 1064-1069.

(46) Duboue-Dijon, E.; Laage, D. Characterization of the Local Structure in Liquid Water by Various Order Parameters. J. Phys. Chem. B 2015, 119, 8406-8418.

(47) Yang, J.; Hou, D.; Ding, Q. Ionic Hydration Structure, Dynamics and Adsorption Mechanism of Sulfate and Sodium Ions in the Surface of Calcium Silicate Hydrate Gel: A Molecular Dynamics Study. Appl. Surf. Sci. 2018, 448, 559-570.

(48) Lee, S. H.; Rossky, P. J. A Comparison of the Structure and Dynamics of Liquid Water at Hydrophobic and Hydrophilic Surfaces - a Molecular Dynamics Simulation Study. J. Chem. Phys. 1994, 100, 3334-3345.

\section{TOC graphic}
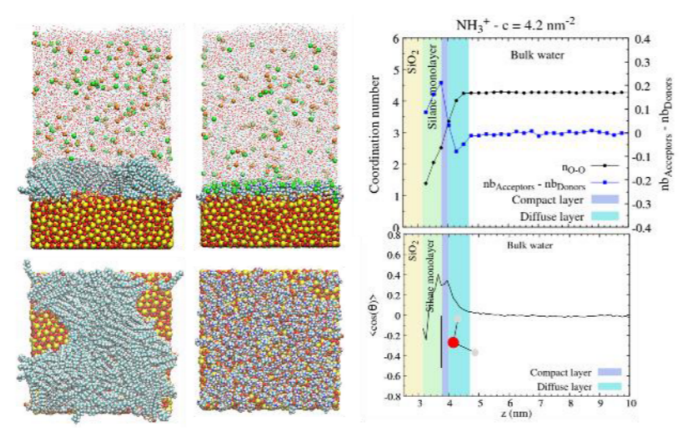